\title{
Estimation of renal function in the intensive care unit: the covert concepts brought to light
}

Sham Sunder, Rajesh Jayaraman*, Himanshu Sekhar Mahapatra, Satyanand Sathi, Venkata Ramanan, Prabhu Kanchi, Anurag Gupta, Sunil Kumar Daksh and Pranit Ram

\begin{abstract}
Frantic efforts have been made up to this date to derive consensus for estimating renal function in critically ill patients, only to open the Pandora's box. This article tries to explore the various methods available to date, the newer concepts, and the uncared issues that may still prove to be useful in estimating renal function in intensive care unit patients. The concept of augmented renal clearance, which is frequently encountered in critically ill patients, should always be taken into account, as correct therapeutic dosage of drugs sounds vital which in turn depends on correctly calculated glomerular filtration rate. Serum creatinine and creatinine-based formulae have their own demerits that are well known and established. While Cockcroft-Gault and 4-variable modification of diet in renal diseases formulae are highly inadequate in the intensive care setup for estimating glomerular filtration rate, employing isotopic methods is impractical and cumbersome. The 6-variable modification of diet in renal diseases formula fairs better as it takes into account the serum albumin and blood urea nitrogen, too. Jelliffe's and modified Jelliffe's equations take into account the rate of creatinine production and volume of distribution which in turn fluctuates heavily in a critically ill patient. Twenty-four-hour and timed creatinine clearances offer values close to reality although not accurate and cannot provide immediate results. Cystatin $C$ is a novel agent that offers a sure promise as it is least influenced by factors that affect serum creatinine to a major extent. Aminoglycoside clearance, although still in the dark area, may prove a simple yet precise way of estimating glomerular filtration rate in those patients in whom these drugs are therapeutically employed. Optic ratiometric method has emerged as the most sophisticated one in glomerular filtration rate estimation in critically ill patients.
\end{abstract}

Keywords: Renal function in ICU, Augmented renal clearance, Cystatin C, MDRD, Optic ratiometric method for GFR

\section{Introduction}

Critically ill patients with acute kidney injury (AKI) do differ from patients who are not ill in so many ways. Many mathematical formulae do exist to estimate the glomerular filtration rate (GFR) in this population of patients. AKI is common among hospitalized patients, especially in critically ill ones [1-6]. A decline in kidney function contributes to the accumulation of many drugs [7-9]. An accurate assessment of kidney function is required to optimize drug administration as both overdosing and underdosing of drugs may prove detrimental in a critically ill patient.

\footnotetext{
*Correspondence: rajsubbuiyer@gmail.com

Department of Nephrology, Post Graduate Institute of Medical Education and Research (PGIMER), Dr. Ram Manohar Lohia Hospital, 15/57, Second floor, Old Rajinder Nagar, New Delhi, Delhi 110060, India
}

\section{Review}

Problems in GFR estimation in an intensive care unit (ICU) set up

Critically ill patients often have rapidly fluctuating renal hemodynamics in the setting of AKI, and changes of GFR are poorly reflected by daily changes in serum creatinine concentrations in patients with AKI [10]. Creatinine as a single parameter always has demerits in non-steady states observed in ICU patients as it is always constantly released into the circulation, affected by many factors including muscle mass and drugs [11-14]. Moreover, creatinine poorly differentiates between prerenal and intrinsic renal failures and approximately 50\% of renal mass has to be lost for the serum creatinine to rise [15].

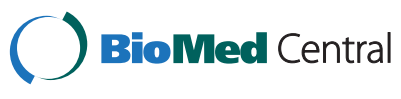

(c) 2014 Sunder et al.; licensee BioMed Central Ltd. This is an Open Access article distributed under the terms of the Creative Commons Attribution License (http://creativecommons.org/licenses/by/2.0), which permits unrestricted use, distribution, and reproduction in any medium, provided the original work is properly credited. The Creative Commons Public Domain Dedication waiver (http://creativecommons.org/publicdomain/zero/1.0/) applies to the data made available in this article, unless otherwise stated 
Often, the phenomenon of augmented renal clearance (ARC) in critically ill patients is either missed or not understood. This is seen in ill patients who are on vasopressors and deliberate fluid support. This is important in calculating the dosage of drugs especially those with narrow therapeutic range.

\section{ARC in critically ill: an enigmatic concept}

ARC is defined as estimated GFR $>130 \mathrm{ml} / \mathrm{min}$. In a study by Andrew Udy et al. [16], 17 of 20 patients (85\%) with traumatic brain injury who required saline infusion and vasopressor agents to maintain the cerebral perfusion pressure had ARC. Using timed urinary creatinine clearance method to measure GFR, ARC was demonstrated in burns $[17,18]$, sepsis [19] and surgery, and in ICU patients. Brown et al. [20] recorded a creatinine clearance of $190 \mathrm{ml} / \mathrm{min} / 1.73 \mathrm{~m}^{2}$ in a cohort of critically ill postoperative patients. Recently, Fuster-Lluch et al. [21] reported an incidence of $17.9 \%$ in a cohort of postoperative and polytrauma patients, who were younger, with lower Acute Physiology And Chronic Health Evaluation (APACHE) II scores, higher diastolic blood pressures, and higher urine output on the first morning of admission to the ICU. Cytokine release from acute injury [22], the innate immune and inflammatory responses to trauma [23], and aggressive fluid resuscitation may promote increased organ blood flow and enhanced excretory function. The importance of the concept is quite obvious. This throws light on the doses of renally excreted drugs and may mean that standard dosing regimens are inadequate in patients with ARC. Baptista et al. [24] examined the performance of four creatinine-based estimation equations in 86 patients with ARC. This post hoc analysis showed that all the better known GFR equations underestimated the measured creatinine clearance value. The list below illustrates the practical problems in estimating GFR in an ICU setup:

1. Rapidly fluctuating renal hemodynamics

2. Both overdosing and underdosing are problems when GFR could not be estimated close to accuracy

3. Constantly changing volume status of the patient

4. Concept of ARC is not frequently applied in calculating GFR leading to inadequate dosing of drugs

5. Commonly used creatinine-based equations are flawed in the critical care setting. Ideal methods like inulin clearance become impractical in an ICU setup

\section{Equations for estimating creatinine clearance/GFR CG formula}

( 140 - Age in years) $\times$ Body weight in $\mathrm{kg} / 72 \times$ Serum creatinine in $\mathrm{mg} / \mathrm{dl}$. If the patient is a female, multiply result by 0.85 (Table one in [25]).

\section{The 4-variable MDRD}

$$
\text { GFR }=186 \times(\text { Serum creatinine })^{-1.154} \times(\text { Age })^{-0.203}
$$

If a patient is female, multiply result by 0.742 and if black, multiply result by 1.212 [25].

\section{The 6-variable MDRD}

$$
\begin{aligned}
\mathrm{GFR}=170 & \times(\text { Serum creatinine })^{-0.999} \times(\text { Age })^{-0.176} \\
& \times(\mathrm{BUN})^{-0.170} \times(\text { Alb })+0.318
\end{aligned}
$$

If female, multiply result by 0.762 and if black, multiply result by 1.18 [25], where $\mathrm{BUN}=$ blood urea nitrogen measured in $\mathrm{mg} / \mathrm{dl}, \mathrm{Alb}=$ serum albumin concentration measured in $\mathrm{g} / \mathrm{dl}$.

Only few studies have attempted to improve estimation of GFR in critically ill patients and these studies included subjects with stable kidney function in various settings [17,26-28].

Relatively accurate estimation of GFR in a non-steady state as in AKI requires timed urine collections, which is not always practically possible in a critically ill patient. To overcome this, Jelliffe introduced an equation in 2002 [29,30].

\section{Jelliffe's equation}

Estimated $\mathrm{GFR}=\{($ Volume of distribution $\times($ Serum creatinine on day $1-$ Serum creatinine on day 2$)\}+$ Creatinine production) 100/1,440/Average serum creatinine $[29,30]$.

Creatinine production $(\mathrm{mg} /$ day) is computed using the following equation:

$$
\begin{aligned}
& {[29.305-(0.203 \times \text { Age })] \times \text { Weight in } \mathrm{kg}} \\
& \times[1.037-(0.0338 \times \text { Average creatinine })] \\
& \times \text { Correction for gender }(0.85 \text { for males and } \\
& \quad 0.765 \text { for females })[29]
\end{aligned}
$$

Jelliffe's equation obviously takes into account the fluctuations of serum creatinine over time, which frequently occurs in AKI in ICU and which is not considered in the above-mentioned Cockcroft-Gault (CG) and Modification of Diet in Renal Diseases (MDRD) formulae. Ongoing creatinine production is also taken into consideration, a major merit. However, this does not consider the fluid balance variations that could also affect the serum creatinine [31]. Creatinine is a watersoluble substance, and rapid, especially overzealous fluid administration can lower the creatinine and falsely overestimate the GFR [32]. To overcome this, a modification was made, which adjusted each measured creatinine to cumulative fluid balance. This requires the 
employment of an entity called correction factor. This was referred to as modified Jelliffe's equation [29].

\section{Modified Jelliffe's equation}

$$
\begin{aligned}
& \text { Adjusted creatinine }= \text { Serum creatinine in } \mathrm{mg} / \mathrm{dl} \\
& \times \text { Correction factor }
\end{aligned}
$$

$$
\begin{aligned}
\text { Correction factor }= & {[\text { Hospital admission weight }(\mathrm{kg})} \\
& \left.\times 0.6+\sum(\text { Daily fluid balance })\right] / \\
& \text { Hospital admission weight } \\
& \times 0.6 \times \text { Creatinine clearance } \\
& \text { in } \mathrm{ml} / \mathrm{min}[29] .
\end{aligned}
$$

The 24-h creatinine clearance is usually determined from a 24-h urine collection [32].

\section{An example}

In a $60-\mathrm{kg}$ woman, if the serum creatinine is $1.4 \mathrm{mg} / \mathrm{dl}$, urine creatinine is $110 \mathrm{mg} / \mathrm{dl}$, and urine volume is $1.4 \mathrm{l} /$ day, then creatinine clearance $=[110 \times 1.4] / 1.4=110 \mathrm{l} /$ day. This value has to be multiplied by 1,000 to convert into milliliter and then divided by 1,440 (the number of minutes in a day) to convert into units of milliliter per minute. Thus, creatinine clearance $=[110 \times 1,000] /$ $1,440=76.4 \mathrm{ml} / \mathrm{min}$.

In a study known as PICARD (Programme to Improve Care in Acute Renal Dysfunction) by Josee Bouchard et al. [33], the GFR was estimated by CG, MDRD, Jelliffe's, and modified Jelliffe's equations and was compared with measured urinary creatinine clearance. Twelve non-dialyzed, non-oliguric patients with consecutive increases in creatinine for at least 3 and up to 7 days were identified and taken into study. The GFR estimated by Jelliffe's and MDRD equations correlated best with urinary creatinine clearance. The degree of overestimation of GFR by CG, MDRD, and Jelliffe was $80 \%$, $33 \%$, and $10 \%$, respectively, and the degree of underestimation of GFR of modified Jelliffe's equation was $2 \%$. The relative overestimation of GFR in AKI with both CG and MDRD will be more prominent when baseline GFR is higher. Small absolute changes in serum creatinine will be reflected as large relative changes in GFR with a lower serum creatinine. Patients with fluid accumulation had GFR overestimated the most by CG and MDRD equations. In practice, it is imperative to adjust GFR for creatinine production and fluid balance at the beginning of an AKI episode, when the initial serum creatinine is within the normal or in the near-normal range.
Jelliffe's and modified Jelliffe's equations can be easily integrated in a computer program to facilitate dosage regimens of drugs that have a narrow therapeutic index. It is important to highlight the magnitude of variation among these available methods because GFR estimation in AKI could be used to adjust drug dosing and could also influence the timing of initiation of renal replacement therapy.

\section{Cystatin C - a real boon in GFR estimation}

Cystatin $\mathrm{C}$ is a non-glycosylated protein produced by all nucleated cells at a constant rate [34]. Its constant rate of production [35], low molecular weight of $13 \mathrm{kDa}$, and positive charge at physiological $\mathrm{pH}$ makes it a suitable marker for glomerular filtration. It is reabsorbed and almost completely catabolized in the proximal tubule $[34,35]$. It is found in relatively high concentrations in many body fluids, especially in the seminal fluid, cerebrospinal fluid, and synovial fluid [36,37]. It has multitude of advantages including its extreme sensitivity to small changes in GFR and higher diagnostic accuracy than MDRD or CG formulae. Moreover, its concentration is least affected by infections, malignancies, steroid therapy, inflammatory disorders, and muscle mass [38-45]. In a study by Patricia Villa et al. [46], serum creatinine, serum cystatin $\mathrm{C}$, and 24-h creatinine clearance were determined in 50 critically ill patients (age 21-86 years; mean APACHE II score $20 \pm 9$ ). Data showed that serum cystatin $C$ correlated better with GFR than creatinine (1/ cystatin $C$ versus creatinine clearance, $r=0.832, P<0.001$; $1 /$ creatinine versus creatinine clearance, $r=0.426, P=$ 0.002). Cystatin $C$ was diagnostically superior to creatinine (area under the curve for cystatin C 0.927 and for creatinine 0.694). Half of the patients had AKI. Only 5 (20\%) of these 25 patients had elevated serum creatinine, whereas $76 \%$ had elevated serum cystatin $C$ levels $(P=0.032)$. This suggests that serum cystatin $C$ is a better marker of GFR than serum creatinine in critically ill patients.

Two equations can be used to estimate GFR from cystatin C concentration:

(A) Grubb's equation [47]: GFR $=83.93 \times$ Cystatin $C^{-1.676}$

(B) Larsson's equation [48]: GFR $=77.239 \times$ Cystatin $\mathrm{C}^{-1.2623}$; cystatin $\mathrm{C}$ is measured in $\mathrm{mg} / \mathrm{l}$.

\section{CG and 4-variable MDRD: woefully inadequate in the} critical care setting

The CG formula was derived from creatinine clearance based on 24-h urine collections in 249 subjects in a medical ward in a veterans administration facility, for which $96 \%$ of patients were men mostly with mild renal dysfunction. The MDRD equation has its origin from a cohort of outpatients based on ${ }^{125} \mathrm{I}$ iothalamate clearances with 
moderate-to-severe renal impairment. An abbreviated 4variable MDRD equation uses only age, sex, race, and serum creatinine level to estimate the renal function. None of these equations has been thoroughly validated among ill hospitalized patients [49,50]. The 6-variable MDRD equation also adds albumin and BUN concentrations into the model. This may be a more appropriate equation in a critical care setup. In a study by Poggio et al. [10], iodine-125 iothalamate clearances performed in 107 sick in-patients with renal dysfunction were compared with estimated GFR from the 6- and 4-variable MDRD and CG equations. Patients were also subdivided into those having BUN/creatinine ratio of $>20$ and $<20$. Compared with iothalamate GFR, the CG and MDRD formulae performed poorly with respect to their ability to predict actual GFR, as shown by their poor agreement and high degree of bias. The 6-variable MDRD equation showed a better concordance correlation coefficient compared with the 4-variable MDRD equation and CG formula (0.66 versus 0.57 and 0.46 , respectively; $P<0.01$ ). High BUN/ creatinine ratios are the usual findings in hospitalized patients, and estimation of GFR in this population does pose a great challenge for the clinicians. In such situations, the 6-variable MDRD may serve as a good option than the other mathematical formulae in arriving at a relatively accurate GFR whereas the same may not offer any advantage over 4-variable MDRD in healthier subjects with preserved BUN/serum creatinine ratio [51-60].

\section{Chronic kidney disease-epidemiology (CKD-EPI) equation in critically ill patients}

CKD-EPI collaboration developed a new equation to measure GFR based on serum creatinine, age, gender, and race:

$$
\begin{aligned}
& \text { CKD-EPI : Estimated GFR } \\
& =141 \times \min (\text { serum creatinine } / k, 1)^{a} \\
& \\
& \times \max (\text { serum creatinine } / k, 1)^{-1.209} \\
& \quad \times 0.993^{\text {age }} \times 1.018(\text { if female }) \\
& \times(1.159 \text { if black })
\end{aligned}
$$

[61] where $k$ is 0.7 for females and 0.9 for male patients, $a$ is -0.329 for female patients and -0.411 for male patients, min indicates the minimum of creatinine $/ k$ or 1 , and max indicates the maximum of creatinine $/ k$ or 1$)$. In comparison to the MDRD equation, CKD-EPI has greater precision and reliability, especially for GFR $>60 \mathrm{ml} / \mathrm{min}$ per $1.73 \mathrm{~m}^{2}$. However, to date, this equation has not been evaluated in hospitalized patients. As its outcome is based on serum creatinine, overestimation of GFR does occur

Table 1 Salient features of various methods that could be employed to measure GFR in ICU setup

\begin{tabular}{lll}
\hline SI no & Methods & Merits \\
\hline 1 & CG formula & Easily computable \\
& \\
& 4-variable MDRD & $\begin{array}{l}\text { More accurate than CG. May offer value close to 6- } \\
\text { variable MDRD in healthier patients with preserved } \\
\text { BUN/Cr ratio }\end{array}$
\end{tabular}

3 6-variable MDRD

$4 \quad$ CKD-EPI formula

$5 \quad$ 24-h creatinine clearance

6 Jelliffe's equation

$7 \quad$ Modified Jelliffe's equation

8 Serum cystatin C

9 Aminoglycoside clearance

10 Fiberoptic ratiometric fluorescent analyzer method
BUN and serum albumin are taken into account. More accurate when BUN/CR ratio is increased. Better concordance correlation coefficient when compared with CG and 4-variable MDRD

Greater precision and reliability when compared with MDRD. More accurate when GFR $>60 \mathrm{ml} / \mathrm{min} / 1.73 \mathrm{~m}^{2}$

More accurate when compared to CG and MDRD formulae

Ongoing creatinine production and fluctuations in creatinine concentration over time are taken into account

Fluid balance variations of creatinine are also taken into account

Less affected by non-renal factors. Sensitive to changes in so-called creatinine blind GFR(40-70 ml/ $\mathrm{min})$; preferred agent in liver disease patients

May serve as an easy method for GFR estimation in patients already on aminoglycosides. May be better than 24-h creatinine clearance

Most accurate way of all. Rapid, inexpensive, reproducible, and safe method

\section{Demerits}

Highly inaccurate in the critical care setup. Considerable degree of GFR overestimation

Dependency on creatinine. May not be accurate when $\mathrm{BUN} / \mathrm{Cr}$ ratio is increased. Does not take into account blood urea nitrogen and albumin. Overestimation of GFR when baseline GFR is high

Dependency on creatinine. Ongoing creatinine production and its fluid balance variations are not taken into account. Less accurate when compared with cystatin $C$ and novel methods

Not validated extensively in hospitalized and sick individuals. Dependency on serum creatinine

Collection of urine is an issue. Cannot provide immediate results. Becomes a problem when rapid administration of drugs is essential

Does not take into account the variations in creatinine concentration with respect to fluid balance

Still less accurate when compared with cystatin $C$ and fiberoptic radiometric methods

Expensive and unreliable in the presence of thyroid dysfunction, may be affected in patients taking high dose steroids with renal dysfunction

Giving aminoglycoside for renal function estimation alone may not be wise or practically possible

Still experimental. Requirement of technical expertise. Scarce studies in humans 
with CKD-EPI equation too, especially in cirrhotic patients with low muscle mass, although much less when compared with CG formula.

\section{Aminoglycoside clearance in urine as a measure of GFR in} critical care patients: where do we stand?

Aminoglycosides might be used to estimate renal function because they are freely filtered, neither secreted nor reabsorbed in the kidney, and have little non-renal clearance. To date, conflicting results have been produced by studies on ICU patients in estimating renal function, both good and poor. This method can be used to estimate renal functions in ICU patients who are therapeutically prescribed aminoglycosides, usually amikacin, gentamycin, and tobramycin according to the dosing standards. In a study by TE Jones et al. in an ICU [62], gentamycin and tobramycin clearance was compared with standard MDRD and CG formulae along with serum cystatin $C$. These aminoglycosides were administered over $30 \mathrm{~min}$ using a computerized pump, and the first blood sample taken 30 min later. The second sample was taken at a time estimated to be twice the half-life of the drugs. These blood samples were also used in the calculations of creatinine clearance from the timed urine collections. The 2-h urine collection was commenced when the aminoglycoside infusion started, and the 24-h collection commenced at the end of the 2$\mathrm{h}$ collection. Gentamycin clearance performed the best, being within $10 \%$ of the value on $44 \%$ of occasions and within $20 \%$ on $78 \%$ of occasions. Gentamycin clearance has previously been shown to be a better estimate of creatinine clearance than the 24-h urine estimate in a study using inulin as the comparator [63-66]. Giving aminoglycosides for the estimation of renal function alone may not be a wise option but in patients who are therapeutically prescribed aminoglycosides, their clearance may serve as one of the better options in estimating renal function.

\section{Optic ratiometric method for GFR estimation: do the advantages outweigh the question of its feasibility in an intensive care setup?}

Novel methods for the rapid estimation of GFR include employment of portable fiberoptic ratiometric fluorescent analyzer, predominantly tested in large animal models, mainly in pigs and dogs, the two species in which the results are supposed to approximate in humans. In this novel method tested in animal models, an optical fiber of $<1$-mm size that delivers excitation light and absorbs fluorescent emissions is inserted into a central vein through a commercial intravenous catheter. A mixture of fluorescent chimeras of a small freely filterable reporter and large non-filterable plasma volume marker is infused as a bolus, excited by light-emitting diodes, and the in vivo signals were detected and quantified by photomultiplier tubes in the tested species within an hour. While the fluorescent chimera is used as a plasma volume marker, the small highly fluorescent and highly filterable reporter molecule is used to quantify the rate of its plasma clearance, which in turn is the measure of GFR. This method allows for the rapid, inexpensive, safe, reproducible, and patient-friendly method of estimating GFR in conditions where only a short time frame is available to make clinical decisions, as in AKI in a critical care setting. Exing Wang et al. [67], in their animal model study, found that the portable fiberoptic ratiometric fluorescent analyzer provided a rapid pointof-care determination of GFR which was standardized against the 6-h iohexol clearance from the plasma. Table 1 summarizes the overall features and characteristics of the parameters and equations that could be employed to estimate GFR in an ICU setup.

\section{Conclusions}

The concept of estimating renal function in critically ill patients had always remained elusive. The issue of ARC should be considered to avoid improper dosing of drugs. CG and 4-variable MDRD equations should better be avoided in ICU setup. Cystatin $\mathrm{C}$, modified Jelliffe's, Jelliffe's, and 6-variable MDRD equations could be employed in that order to estimate renal function and to provide instant and accurate results. While aminoglycoside clearance could be used in patients in whom they are therapeutically used, optic ratiometric method provides the most accurate and instant estimation of renal function in critically ill patients, although large-scale studies in humans are required to validate it.

\section{Abbreviations}

AKI: acute kidney injury; APACHE: acute physiology and chronic health evaluation score; ARC: augmented renal clearance; BUN: blood urea nitrogen; CG: Cockcroft-Gault; CKD-EPI: chronic kidney disease-epidemiological equation; GFR: glomerular filtration rate; ICU: intensive care unit; MDRD: modification of diet in renal diseases.

\section{Competing interests}

The authors declare that they have no competing interests.

\section{Authors' contributions}

$\mathrm{SS}$ and $\mathrm{RJ}$ are the main authors who have taken part in the acquisition of data, analysis and interpretation of the data, and in drafting and revision of the manuscript. SA, VR, PK, and AG were involved in drafting and critical revision of the manuscript. SKD, PR, and HM were involved in the final approval of the version to be published. All the nine authors have read and approved the final manuscript.

Received: 13 January 2014 Accepted: 17 April 2014

Published: 7 May 2014

\section{References}

1. Hou SH, Bushinsky DA, Wish JB, Cohen JJ, Harrington JT: Hospital-acquired renal insufficiency: a prospective study. Am J Med 1983, 74:243-248.

2. Nash K, Hafeez A, Hou S: Hospital-acquired renal insufficiency. Am J Kidney Dis 2002, 39:930-936. 
3. Chertow GM, Burdick E, Honour M, Bonventre JV, Bates DW: Acute kidney injury, mortality, length of stay, and costs in hospitalized patients. J Am Soc Nephrol 2005, 16:3365-3370.

4. Lassnigg A, Schmidlin D, Mouhieddine M, Bachmann LM, Druml W, Bauer P, Hiesmayr M: Minimal changes of serum creatinine predict prognosis in patients after cardiothoracic surgery: a prospective cohort study. J Am Soc Nephrol 2004, 15:1597-1605.

5. Druml W: Acute renal failure is not a "cute" renal failure! Intensive Care Med 2004, 30:1886-1890.

6. Druml W, Lax F, Grimm G, Schneeweiss B, Lenz K, Laggner AN: Acute renal failure in the elderly 1975-1990. Clin Nephrol 1994, 41:342-349.

7. Matzke GR, McGory RW, Halstenson CE, Keane WF: Pharmacokinetics of vancomycin in patients with various degrees of renal function. Antimicrob Agents Chemother 1984, 25:433-437.

8. Smith CR, Moore RD, Lietman PS: Studies of risk factors for aminoglycoside nephrotoxicity. Am J Kidney Dis 1986, 8:308-313.

9. Matzke GR, Frye RF: Drug administration in patients with renal insufficiency. Minimising renal and extrarenal toxicity. Drug Saf 1997, $16: 205-231$.

10. Poggio ED, Nef PC, Wang X, Greene T, Van Lente F, Dennis WW, Hall PM: Performance of the Cockcroft-Gault and modification of diet in renal disease equations in estimating GFR in ill hospitalized patients. Am J Kidney Dis 2005, 46:242-252.

11. Jacobs SC, Ramey JR, Sklar GN, Bartlett ST: Laparoscopic kidney donation from patients older than 60 years. J Am Coll Surg 2004, 198:892-897.

12. Fehrman-Ekholm I, Duner F, Brink B, Tyden G, Elinder CG: No evidence of accelerated loss of kidney function in living kidney donors: results from a cross-sectional follow-up. Transplantation 2001, 72:444-449.

13. Rapoport A, Husdan H: Endogenous creatinine clearance and serum creatinine in the clinical assessment of kidney function. CMAJ 1968, 99:149-156.

14. Burke TJ, Arnold PE, Gordon JA, Bulger RE, Dobyan DC, Schrier RW: Protective effect of intrarenal calcium membrane blockers before or after renal ischemia: functional, morphological, and mitochondrial studies. J Clin Invest 1984, 74:1830-1841.

15. Tomlanovich S, Golbetz H, Perlroth M, Stinson E, Myers BD: Limitations of creatinine in quantifying the severity of cyclosporine-induced chronic nephropathy. Am J Kidney Dis 1986, 8:332-337.

16. Udy A, Boots R, Senthuran S, Stuart J, Deans R, Lassig-Smith M, Lipman J: Augmented creatinine clearance in traumatic brain injury. Anesth Analg 2010, 111:1505-1510.

17. Conil JM, Georges B, Fourcade O, Seguin T, Lavit M, Samii K, Houin G, Tack I, Saivin S: Assessment of renal function in clinical practice at the bedside of burn patients. Br J Clin Pharmacol 2007, 63:583-594

18. Loirat P, Rohan J, Baillet A, Beaufils F, David R, Chapman A: Increased glomerular filtration rate in patients with major burns and its effect on the pharmacokinetics of tobramycin. N Engl J Med 1978, 299:915-919.

19. Lipman J, Wallis SC, Boots RJ: Cefepime versus cefpirome: the importance of creatinine clearance. Anesth Analg 2003, 97:1149-1154.

20. Brown R, Babcock R, Talbert J, Gruenberg J, Czurak C, Campbell M: Renal function in critically ill postoperative patients: sequential assessment of creatinine osmolar and free water clearance. Crit Care Med 1980, 8:68-72.

21. Fuster-Lluch O, Geronimo-Pardo M, Peyro-Garcia R, Lizan-Garcia M: Glomerular hyperfiltration and albuminuria in critically ill patients. Anaesth Intensive Care 2008, 36:674-680.

22. Ott L, McClain CJ, Gillespie M, Young B: Cytokines and metabolic dysfunction after severe head injury. J Neurotrauma 1994, 11:447-472.

23. Kohl BA, Deutschman CS: The inflammatory response to surgery and trauma. Curr Opin Crit Care 2006, 12:325-332.

24. Baptista JP, Udy AA, Sousa E, Pimentel J, Wang L, Roberts JA, Lipman J: A comparison of estimates of glomerular filtration in critically ill patients with augmented renal clearance. Crit Care 2011, 15:R139.

25. Hoste EA, Damen J, Vanholder RC, Lameire NH, Delanghe JR, Van den Hauwe K, Colardyn FA: Assessment of renal function in recently admitted critically ill patients with normal serum creatinine. Nephrol Dial Transplant 2005, 20:748

26. Le Bricon T, Leblanc I, Benlakehal M, Gay-Bellile C, Erlich D: Boudaoud S: Evaluation of renal function in intensive care: plasma cystatin $C$ versus creatinine and derived glomerular filtration rate estimates. Clin Chem Lab Med 2005, 43:953-957.

27. Robert S, Zarowitz BJ, Peterson EL, Dumler F: Predictability of creatinine clearance estimates in critically ill patients. Crit Care Med 1993, 21:1487-1495.
28. Hoste EA, Damen J, Vanholder RC, Lameire NH, Delanghe JR, Van den Hauwe K, Colardyn FA: Assessment of renal function in recently admitted critically ill patients with normal serum creatinine. Nephrol Dial Transplant 2005, 20:747-753.

29. Jelliffe R: Estimation of creatinine clearance in patients with unstable renal function, without a urine specimen. Am J Nephrol 2002, 22:320-324.

30. Jelliffe $R$, Jelliffe $S$ : A computer program for estimation of creatinine clearance from unstable serum creatinine levels, age, sex, and weight. Math Biosci 1972, 14:17-24.

31. Moran SM, Myers BD: Course of acute renal failure studied by a model of creatinine kinetics. Kidney Int 1985, 27:928-937.

32. van Acker BA, Koomen GC, Koopman MG, de Waart DR, Arisz L: Creatinine clearance during cimetidine administration for measurement of glomerular filtration rate. Lancet 1992, 340:1326-1329.

33. Bouchard J, Macedo E, Soroko S, Chertow GM, Himmelfarb J, Ikizler TA Paganini EP, Mehta RL, Program to Improve Care in Acute Renal Disease: Comparison of methods for estimating glomerular filtration rate in critically ill patients with acute kidney injury. Nephrol Dial Transplant 2010, 25(1):102-107

34. Abrahamson M, Olafsson I, Palsdottir A, Ulvsback M, Lundwall A, Jensson O, Grubb A: Structure and expression of the human cystatin $C$ gene. Biochem J 1990, 268:287-294.

35. Abrahasom M, Barret AJ, Salveson G, Grubb A: Isolation of six cysteine protease inhibitors from human urine. J Biol Chem 1986, 261:11282-11289.

36. Grubb A: Diagnostic value of analysis of cystatin $\mathrm{C}$ and protein $\mathrm{HC}$ in biological fluids. Clin Nephrol 1992, 38(Suppl 1):S20-S27.

37. Tenstad O, Roald AB, Grubb A, Aukland K: Renal handling of radiolabelled human cystatin C in the rat. Scand J Clin Lab Invest 1996, 56:409-414

38. Herget-Rosenthal S, Trabold S, Pietruck F, Holtmann M, Philipp T, Kribben A, Cystatin C: Efficacy as screening test for reduced glomerular filtration rate. Am J Nephrol 2000, 20:97-102

39. Jung $\mathrm{K}$, Jung $\mathrm{M}$ : Cystatin $\mathrm{C}$ : a promising marker of glomerular filtration rate to replace creatinine. Nephron 1995, 70:370-371.

40. Newman DJ, Thakkar H, Hedward RG, Wilkie M, White T, Grubb A, Price CP: Serum cystatin $C$ measured by automated immunoassay: a more sensitive marker of changes in GFR than serum creatinine. Kidney Int 1995, 47:312-318

41. Stickle D, Cole B, Hock K, Hruska KA, Scott MG: Correlation of plasma concentrations of cystatin $C$ and creatinine to inulin clearance in pediatric population. Clin Chem 1998, 44:1334-1338.

42. Risch L, Blumberg A, Huber AR: Assessment of function renal in renal transplant patients using cystatin C. A comparison to other renal function markers and estimates. Ren Fail 2001, 23:439-448.

43. Le Bricon $T$, Thervet $E$, Benlakehal M, Bousquet $B$, Legendre $C$, Erlich D: Changes in plasma cystatin $C$ after renal transplantation and acute rejection in adults. Clin Chem 1999, 45:2243-2249.

44. Randers E, Erlandsen EJ: Serum cystatin $\mathrm{C}$ as endogenous marker of the renal function. Clin Chem Lab Med 1999, 37:389-395.

45. Finney $\mathrm{H}$, Newman DJ, Price $\mathrm{CP}$ : Adult reference for serum cystatin $\mathrm{C}$, creatinine and predicted creatinine clearance. Ann Clin Biochem 2000, 37:49-59.

46. Villa $P$, Jiménez $M$, Soriano MC, Manzanares J, Casasnovas P: Serum cystatin C concentration as a marker of acute renal dysfunction in critically ill patients. Crit Care 2005, 9:R139-R143.

47. Grubb A, Nyman U, Björk J, Lindström V, Rippe B, Sterner G, Christensson A: Simple cystatin C-based prediction equations for glomerular filtration rate compared with the modification of diet in renal disease prediction equation for adults and the Schwartz and the Counahan-Barratt prediction equations for children. Clin Chem 2005, 51:1420-1431.

48. Larsson A, Malm J, Grubb A, Hansson LO: Calculation of glomerular filtration rate expressed in $\mathrm{mL} / \mathrm{min}$ from plasma cystatin $C$ values in $\mathrm{mg} /$ L. Scand J Clin Lab Invest 2004, 64:25-30.

49. Cockcroft DW, Gault MH: Prediction of creatinine clearance from serum creatinine. Nephron 1976, 16:31-41.

50. Levey AS, Bosch JP, Lewis JB, Greene T, Rogers N, Roth D: A more accurate method to estimate glomerular filtration rate from serum creatinine: a new prediction equation. Modification of Diet in Renal Disease Study Group. Ann Intern Med 1999, 130:461-470.

51. Levey AS, Greene T, Kusek JW, Beck GJ: A simplified equation to predict glomerular filtration rate from serum creatinine. J Am Soc Nephrol 2000, $11: 155 \mathrm{~A}$. 
52. Wells $\mathrm{M}$, Lipman J: Measurements of glomerular filtration in the intensive care unit are only a rough guide to renal function. S Afr I Surg 1997, 35:20-23.

53. Robert $\mathrm{S}$, Zarowitz BJ: Is there a reliable index of glomerular filtration rate in critically ill patients? DICP 1991, 25:169-178.

54. Bostom AG, Kronenberg F, Ritz E: Predictive performance of renal function equations for patients with chronic kidney disease and normal serum creatinine levels. J Am Soc Nephrol 2002, 13:2140-2144.

55. Hallan S, Asberg A, Lindberg M, Johnsen H: Validation of the modification of diet in renal disease formula for estimating GFR with special emphasis on calibration of the serum creatinine assay. Am J Kidney Dis 2004, 44:84-93.

56. Mariat C, Alamartine E, Barthelemy JC, De Filippis JP, Thibaudin D, Berthoux $P$, Laurent $B$, Thibaudin L, Berthoux F: Assessing renal graft function in clinical trials: can tests predicting glomerular filtration rate substitute for a reference method? Kidney Int 2004, 65:289-297.

57. Vervoort $\mathrm{G}$, Willems $\mathrm{HL}$, Wetzels JF: Assessment of glomerular filtration rate in healthy subjects and normoalbuminuric diabetic patients: validity of a new (MDRD) prediction equation. Nephrol Dial Transplant 2002, 17:1909-1913.

58. Poggio ED, Wang X, Greene T, Van Lente F, Hall PM: Performance of the modification of diet in renal disease and Cockcroft-Gault equations in the estimation of GFR in health and in chronic kidney disease. J Am Soc Nephrol 2005, 16:459-466.

59. Rule AD, Larson TS, Bergstralh EJ, Slezak JM, Jacobsen SJ, Cosio FG: Using serum creatinine to estimate glomerular filtration rate: accuracy in good health and in chronic kidney disease. Ann Intern Med 2004, 141:929-937.

60. Knight EL, Verhave JC, Spiegelman D, Hillege HL, de Zeeuw D, Curhan GC, de Jong PE: Factors influencing serum cystatin $C$ levels other than renal function and the impact on renal function measurement. Kidney Int 2004, 65:1416-1421.

61. Jeong TD, Lee W, Chun S, Lee SK, Ryu JS, Min WK, Park JS: Comparison of the MDRD study and CKD-EPI equations for the estimation of the glomerular filtration rate in the Korean general population. Kidney Blood Press Res 2013, 37:443-450.

62. Jones TE, Peter JV, Field J: Aminoglycoside clearance is a good estimate of creatinine clearance in intensive care unit patients. Anaesth Intensive Care 2009, 37:944-952.

63. Deeter RG, Krauss EA, Penn F, Nahaczewski AE: Comparison of aminoglycoside clearance and calculated serum creatinine clearances. Ther Drug Monit 1989, 11:155-161.

64. Nakahiro RK, Okamoto MP, Chin A, Gill MA, Chae JS, Sclar DA: Use of gentamicin clearance in estimating renal function. Clin Pharm 1992, 10:931-934.

65. Hickling KG, Begg EJ, Perry RE, Atkinson HC, Sharman JR: Serum aminoglycoside clearance is predicted as poorly by renal aminoglycoside clearance as by creatinine clearance in critically ill patients. Crit Care Med 1991, 19:1041-1047.

66. Zarowitz BJ, Robert S, Peterson EL: Prediction of glomerular filtration rate using aminoglycoside clearance in critically ill medical patients. Ann Pharmacother 1992, 26:1205-1210.

67. Wang E, Meier DJ, Sandoval RM, Von Hendy-Willson VE, Pressler BM, Bunch RM, Alloosh M, Sturek MS, Schwartz GJ, Molitoris BA: A portable fiberoptic ratiometric fluorescence analyzer provides rapid point-of-care determination of glomerular filtration rate in large animals. Kid Int 2012, 81:112-117.

doi:10.1186/2052-0492-2-31

Cite this article as: Sunder et al: Estimation of renal function in the intensive care unit: the covert concepts brought to light. Journal of Intensive Care 2014 2:31.

\section{Submit your next manuscript to BioMed Central and take full advantage of:}

- Convenient online submission

- Thorough peer review

- No space constraints or color figure charges

- Immediate publication on acceptance

- Inclusion in PubMed, CAS, Scopus and Google Scholar

- Research which is freely available for redistribution

Submit your manuscript at www.biomedcentral.com/submit 